\title{
Cationic Copolymerization of 1,3-Dioxolane with Tetrahydrofuran Initiated with Methyl Fluorosulfate
}

\author{
Yasuaki YoKoyama, Masahiko OKADA, and Hiroshi Sumitomo \\ Faculty of Agriculture, Nagoya University, Chikusa, Nagoya 464, Japan.
}

(Received January 31, 1979)

\begin{abstract}
Cationic copolymerization of 1,3-dioxolane (DOL) with tetrahydrofuran (THF) was carried out in chloroform at $0^{\circ} \mathrm{C}$ with methyl fluorosulfate $\left(\mathrm{CH}_{3} \mathrm{OSO}_{2} \mathrm{~F}\right)$ and triethyloxonium tetrafluoroborate $\left(\mathrm{Et}_{3} \mathrm{OBF}_{4}\right)$ as initiators. The gas chromatographic determination of the residual monomers during the copolymerization revealed that both DOL and THF were consumed concurrently from the initial stage of the polymerization with $\mathrm{CH}_{3} \mathrm{OSO}_{2} \mathrm{~F}$. With $\mathrm{Et}_{3} \mathrm{OBF}_{4}$, on the other hand, only THF was consumed at first, followed by the rapid consumption of DOL after an induction period. The fractionation of the reaction products and the microstructural analysis by ${ }^{1} \mathrm{H}$ and ${ }^{13} \mathrm{C}$ NMR spectroscopy showed that the products obtained with $\mathrm{CH}_{3} \mathrm{OSO}_{2} \mathrm{~F}$ were real copolymers containing an appreciable ammount of cross-over diads, while those with $\mathrm{Et}_{3} \mathrm{OBF}_{4}$ were block copolymers and/or mixtures of homopolymers. The structures and reactivities of the growing species in these two copolymerization systems are discussed on the basis of these findings.

KEY WORDS 1,3-Dioxolane / Tetrahydrofuran / Copolymerization / NMR/

Random Copolymer / Block Copolymer / Ionic Species / Ester Species /

Methyl Fluorosulfate /
\end{abstract}

In a previous paper, ${ }^{1}$ we reported kinetic studies on the cationic polymerization of 1,3-dioxolane (DOL) initiated with methyl fluorosulfate $\left(\mathrm{CH}_{3} \mathrm{OSO}_{2} \mathrm{~F}\right)$ in deuteriochloroform, and concluded that the polymerization proceeded through an ester growing species, although the coexistence of an undetectable amount of oxonium ionic growing species can not be ruled out. This conclusion was drawn on the basis of a large negative value of the activation entropy $\left[\Delta S_{\mathrm{p}}^{\neq}=-42 \mathrm{cal} \mathrm{mol}^{-1} \mathrm{deg}^{-1}\right.$ $\left(-176 \mathrm{~J} \mathrm{k}^{-1} \mathrm{~mol}^{-1}\right)$ ], which is characteristic of dipole-dipole $\mathrm{S}_{\mathrm{N}} 2$ reactions producing ionic species, e.g., the Menschutkin reaction, together with ${ }^{1} \mathrm{H}$ and ${ }^{13} \mathrm{C}$ NMR scpectral data of the reaction system. This paper describes the cationic copolymerization of DOL with THF which was undertaken in chloroform using two different initiators, $\mathrm{CH}_{3} \mathrm{OSO}_{2} \mathrm{~F}$ and $\mathrm{Et}_{3} \mathrm{OBF}_{4}$, in order to make clear the reactivity of the ester growing species in the polymerization of DOL.

The cationic copolymerization of DOL with THF using stable oxonium salts as initiators has been attempted by two research groups. ${ }^{2,3}$ Yamashita $e t$ $a .^{2}$ confirmed by the gas chromatographic de- termination of the unreacted monomers during the copolymerization initiated with $\mathrm{Et}_{3} \mathrm{OBF}_{4}$ that preferential polymerization of THF occurred in the initial stage of the copolymerization, and that once DOL began to polymerize after an induction period, the polymerization of THF slowed down gradually and eventually ceased. However, it was resumed, although very slowly, after the polymerization of DOL reached the equilibrium conversion. Lyudvig et $a l^{3}$ studied the same copolymerization with $\mathrm{Et}_{3} \mathrm{OSbCl}_{6}$ as an initiator and they concluded that the propagating species of DOL, which are supposedly solvated by THF monomers, grow only by the addition of DOL monomers, in agreement with the results of Yamashita et al. ${ }^{2}$

It seems strange at first glance that DOL cannot copolymerize with THF, because both $\mathrm{DOL}^{4.5}$ and THF $^{6,7}$ copolymerize with 3,3-bischloromethyloxacyclobutane (BCMO), and both growing species of DOL and THF grow essentially by the $\mathrm{S}_{\mathrm{N}} 2$ mechanism, although the former has an oxycarbenium ionic character ${ }^{8-11}$ and the latter is a tertiary oxonium ion. ${ }^{12}$ One of the possible reasons for the reluctant cross-over propagations in the DOL-THF 
copolymerization system is the preferential occurrence of an oxonium ion exchange reaction at the growing chain end with DOL and THF units as the penultimate and terminal units, respectively. ${ }^{2}$ Therefore, it would be expected that if the copolymerization is carried out under the conditions where propagations proceed through ester species, instead of ionic species, by using a superacid derivative as an initiator, a random copolymer might be formed from DOL and THF. Conversely, if a random copolymer is actually obtained, it would be taken as a strong support for the presence of an ester species in the polymerization of DOL initiated with a superacid derivative. In this paper, we report the results of the cationic copolymerization of DOL with THF initiated with $\mathrm{CH}_{3} \mathrm{OSO}_{2} \mathrm{~F}$ and $\mathrm{Et}_{3} \mathrm{OBF}_{4}$, and discuss the structures and reactivities of the growing species.

\section{EXPERIMENTAL}

\section{Materials}

1,3-Dioxolane (DOL) was prepared according to the procedure described by Astle et al., ${ }^{13}$ dried over metallic sodium, and fractionally distilled from calcium hydride. bp $75-76^{\circ} \mathrm{C}$. Tetrahydrofuran (THF) was dried over, and distilled from, metallic sodium, bp $66^{\circ} \mathrm{C}$. Commercial methyl fluorosulfate $\left(\mathrm{CH}_{3} \mathrm{OSO}_{2} \mathrm{~F}\right)$ was purified by distillation. bp 92 $94^{\circ} \mathrm{C}$. Triethyloxonium tetrafluoroborate $\left(\mathrm{Et}_{3} \mathrm{OBF}_{4}\right)$ was prepared by the method of Meerwein et al. ${ }^{14}$ Chhoroform was washed with sulfuric acid, dilute aqueous sodium carbonate, and water successively, and dried over anhydrous sodium sulfate; distillation followed. bp $61^{\circ} \mathrm{C}$.

\section{Copolymerization}

Prescribed amounts of monomers, chloroform, and a chloroform solution containing the initiator were introduced in this order into a glass ampule under a nitrogen atmosphere. The ampule was then cooled at liquid nitrogen temperature, sealed off, and kept at $0^{\circ} \mathrm{C}$ for a desired time. The copolymerization was terminated by the addition of a few $\mathrm{ml}$ of a methanol-trimethylamine (volume ratio, $4: 1$ ) solution. The mixture was poured into a large amount of methanol. The precipitate was purified by reprecipitation from its chloroform solution into methanol (methanol-insoluble polymer). The methanol solution was concentrated under reduced pressure. The residue was dissolved in $50 \mathrm{ml}$ of chloroform, and the solution was washed with $10 \mathrm{ml}$ of water three times. The solvent was evaporated and the residue was dried under vacuum to a constant weight (methanol-soluble polymer).

\section{Characterization of Copolymers}

${ }^{1} \mathrm{H}$ and ${ }^{13} \mathrm{C}$ NMR spectra were taken in deuteriochloroform, using tetramethylsilane as an internal standard at room temperature. The former were recorded on a JNM MH-100 spectrometer working at $100 \mathrm{MHz}$, and the latter on a JNM FX100 Fourier transform spectrometer at $25 \mathrm{MHz}$. The number average molecular weight of the copolymers was determined by a Hewlett Packard vapor pressure osmometer Model 302 on solutions in benzene at $37^{\circ} \mathrm{C}$.

\section{Fractionation of Copolymer}

A sample of copolymer $(0.30 \mathrm{~g})$ was dissolved in a few $\mathrm{ml}$ of chloroform. To this solution was added a large volume of hexane to precipitate the insoluble polymer (insoluble fraction 1). The supernatant solution was separated by decantation, and the solvent was evaporated under reduced pressure to recover the hexane-soluble polymer (soluble fraction 1). The hexane-insoluble fraction was dissolved again in chloroform, and the above procedure was repeated to give soluble fraction 2 and insoluble fraction 2. This cycle was repeated two more times to obtain soluble fractions 3 and 4 and insoluble fraction 4.

\section{Syntheses of Model Compounds}

3,6,8,11-Tetraoxatetradecane.Paraformaldehyde $\left(3.74 \mathrm{~g}, 0.12_{4} \mathrm{~mol}\right)$, ethylene glycol monoethyl ether $\left(22.6 \mathrm{~g}, 0.25_{1} \mathrm{~mol}\right), 50 \mathrm{ml}$ of benzene, and a small amount of $p$-toluenesulfonic acid were introduced into a flask with a water separating apparatus. The mixture was refluxed for about three hours until a predetermined amount of water was distilled off. Then the solution was neutralized with sodium carbonate and distilled. bp $87-88^{\circ} \mathrm{C}[10 \mathrm{mmHg}$ $(1.33 \mathrm{kPa})]$; yield, $62.8 \%$; ${ }^{1} \mathrm{H}$ NMR $\delta 1.22\left(\mathrm{CH}_{3}-\right.$, $6 \mathrm{H}), c a .3 .6\left(-\mathrm{OCH}_{2}-, 12 \mathrm{H}\right)$, and $4.74\left(-\mathrm{OCH}_{2} \mathrm{O}-\right.$, 2H) ppm; ${ }^{13} \mathrm{C}$ NMR $\delta 15.2\left(\mathrm{CH}_{3}-\right), 66.5,66.9$, and $69.7\left(-\mathrm{OCH}_{2}-\right)$, and $95.1\left(-\mathrm{OCH}_{2} \mathrm{O}-\right)$ ppm.

3,6,8-Trioxadodecane. 3,6,8,11-Tetraoxatetradecane $(5.05 \mathrm{~g}, 26.2 \mathrm{mmol})$, butyl alcohol $(3.00 \mathrm{~g}, 40.5 \mathrm{mmol})$, and a small amount of $p$ - toluenesulfonic acid were placed into a flask, and the 
mixture was refluxed for one hour. Then the solution was neutralized with sodium carbonate and distilled. bp $79-80^{\circ} \mathrm{C}[24 \mathrm{mmHg}(3.20 \mathrm{kPa})]$; yield, $18.6 \% ;{ }^{\circ} \mathrm{H}$ NMR $\delta 0.94\left(\mathrm{CH}_{3}-, 3 \mathrm{H}\right), 1.23\left(\mathrm{CH}_{3}-, 3 \mathrm{H}\right), 1.54$ $\left(-\mathrm{CH}_{2}-, 4 \mathrm{H}\right), \mathrm{ca} .3 .6\left(-\mathrm{OCH}_{2}-, 8 \mathrm{H}\right)$, and 4.77 $\left(-\mathrm{OCH}_{2} \mathrm{O}-, 2 \mathrm{H}\right) \mathrm{ppm} ;{ }^{13} \mathrm{C}$ NMR $\delta 13.8$ and 15.1 $\left(\mathrm{CH}_{3}-\right), 19.4\left(-\mathrm{CH}_{2}-\right), 31.8\left(-\mathrm{CH}_{2}-\right), 66.6,66.8,67.6$, and $69.8\left(-\mathrm{OCH}_{2}-\right)$, and $95.3\left(-\mathrm{OCH}_{2} \mathrm{O}-\right)$ ppm.

\section{RESULTS}

\section{Cationic Copolymerization of DOL with THF}

The cationic copolymerizations of DOL with THF initiated with $\mathrm{CH}_{3} \mathrm{OSO}_{2} \mathrm{~F}$ and $\mathrm{Et}_{3} \mathrm{OBF}_{4}$ were carried out in chloroform. The conversions and the mole fractions of DOL and THF units in the products were calculated by the gas chromatographic determination of the residual monomers during the copolymerizations. Figure 1 shows the timeconversion curves in the copolymerization of DOL with THF initiated with $\mathrm{CH}_{3} \mathrm{OSO}_{2} \mathrm{~F}$ and $\mathrm{Et}_{3} \mathrm{OBF}_{4}$. The apparent rate of propagation in the copolymerization initiated with $\mathrm{CH}_{3} \mathrm{OSO}_{2} \mathrm{~F}$ is lower than that initiated with $\mathrm{Et}_{3} \mathrm{OBF}_{4}$. The difference in the copolymerization behavior between the two initiator series is emphasized in the plots of mole fraction of DOL unit in the products and the conversion (Figure 2).

In the copolymerization initiated with $\mathrm{Et}_{3} \mathrm{OBF}_{4}$, only THF is consumed at the initial stage of the copolymerization, and DOL is consumed rapidly after an induction period. This phenomenon is essentially the same as that reported previously. ${ }^{2} \mathrm{On}$ the other hand, when $\mathrm{CH}_{3} \mathrm{OSO}_{2} \mathrm{~F}$ is used as initiator, DOL is consumed more rapidly than THF from the initial stage of the copolymerization after a prolonged induction period (Figures 1 and 2). Such a polymerization behavior suggests that the reactivities of the growing species of DOL and THF in the latter copolymerization system are different from those in the former system.

The results of the copolymerization of DOL with THF are summarized in Table I. The yields were calculated from the weight of the isolated polymers. The copolymers obtained with $\mathrm{CH}_{3} \mathrm{OSO}_{2} \mathrm{~F}$ (Runs $2-5)$ were highly viscous or waxy materials, and their average molecular weights were appreciably lower than those of the homopolymers obtained with the same initiator (Runs 1 and 6) and the copolymer prepared with $\mathrm{Et}_{3} \mathrm{OBF}_{4}$ (Run 7).

Figure 3 shows a typical ${ }^{1} \mathrm{H}$ NMR spectrum of the

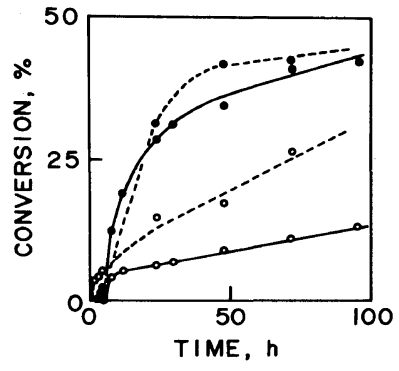

Figure 1. Time-conversion curves in copolymerization of DOL with THF: Total monomers, $10 \mathrm{~mol} \mathrm{dm}^{-3}$; solvent, $\mathrm{CHCl}_{3}$; temp, $0^{\circ} \mathrm{C}$; mole fraction of DOL in feed, 0.50 ; initiator, (-), $\mathrm{CH}_{3} \mathrm{OSO}_{2} \mathrm{~F}$ and (--) $\mathrm{Et}_{3} \mathrm{OBF}_{4}$; monomer, DOL and $\bigcirc$, THF.

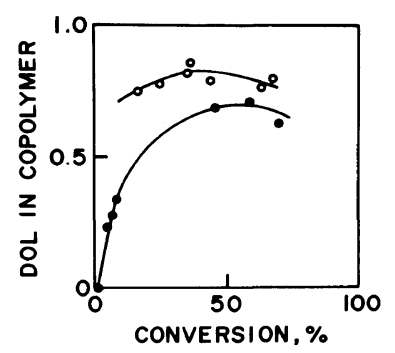

Figure 2. Mole fraction of DOL in copolymer $v s$. conversion (based on mol \%) in copolymerization of DOL with THF: temp, $0^{\circ} \mathrm{C}$; solvent, $\mathrm{CHCl}_{3}$; mole fraction of DOL in feed, $0.50 ; \mathrm{O}, \mathrm{CH}_{3} \mathrm{OSO}_{2} \mathrm{~F}$; $\mathrm{Et}_{3} \mathrm{OBF}_{4}$.

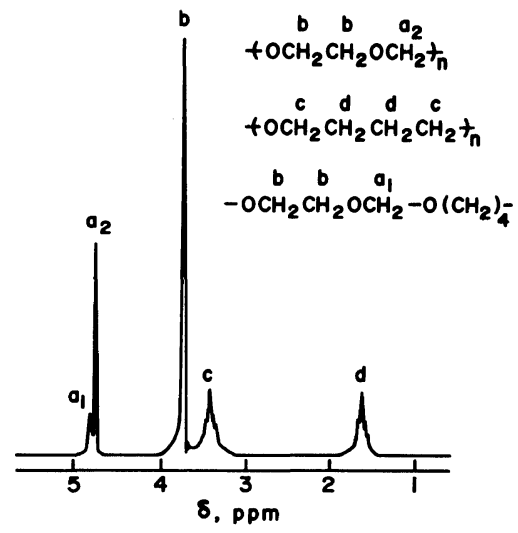

Figure 3. ${ }^{1} \mathrm{H}$ NMR spectrum of DOL-THF copolymer: mole fraction of DOL in copolymer, $0.60_{0} ; \mathrm{CDCl}_{3}$; ca. $10 \%$, room temp.

copolymer. From the ${ }^{1} \mathrm{H}$ NMR spectra of the homopolymers of DOL and THF, the peaks $\mathrm{a}_{2}, \mathrm{~b}, \mathrm{c}$, and $\mathrm{d}$ are assigned as follows. 
Y. Yokoyama, M. OKada, and H. Sumitomo

Table I. Copolymerization of DOL with $\mathrm{THF}^{\mathrm{a}}$

\begin{tabular}{|c|c|c|c|c|c|}
\hline $\begin{array}{c}\text { Sample } \\
\text { No. }\end{array}$ & $\begin{array}{c}\text { Mole fraction } \\
\text { of DOL } \\
\text { in feed }\end{array}$ & $\frac{\text { Time }}{\mathrm{h}}$ & $\begin{array}{c}\text { Fraction } \\
\text { No. }^{\mathrm{b}}\end{array}$ & $\frac{\text { Yield }}{\%}$ & $M W^{\circ}$ \\
\hline 1 & 0.00 & 48 & $\begin{array}{r}\text { I } \\
\text { II }\end{array}$ & $\begin{array}{c}50.6 \\
-\end{array}$ & $\begin{array}{c}5700 \\
-\end{array}$ \\
\hline 2 & 0.20 & 96 & $\begin{array}{r}\text { I } \\
\text { II }\end{array}$ & $\begin{array}{r}9.2 \\
15.6\end{array}$ & $\begin{array}{l}2300 \\
2000\end{array}$ \\
\hline 3 & 0.50 & 48 & $\begin{array}{r}\text { I } \\
\text { II }\end{array}$ & $\begin{array}{r}10.1 \\
4.8\end{array}$ & $\begin{array}{r}1400 \\
900\end{array}$ \\
\hline 4 & 050 & 96 & $\begin{array}{r}\text { I } \\
\text { II }\end{array}$ & $\begin{array}{r}19.3 \\
9.0\end{array}$ & $\begin{array}{r}1400 \\
900\end{array}$ \\
\hline 5 & 0.80 & 96 & $\begin{array}{r}\text { I } \\
\text { II }\end{array}$ & $\begin{array}{r}34.3 \\
9.3\end{array}$ & $\begin{array}{l}2200 \\
1000\end{array}$ \\
\hline 6 & 1.00 & 48 & $\begin{array}{l}\text { I } \\
\text { II }\end{array}$ & $\begin{array}{r}21.2 \\
1.4\end{array}$ & $\begin{array}{l}6500 \\
9000\end{array}$ \\
\hline $7^{\mathrm{d}}$ & 050 & 48 & $\begin{array}{r}\text { I } \\
\text { II }\end{array}$ & $\begin{array}{r}24.5 \\
7.4\end{array}$ & $\begin{array}{l}7400 \\
1300\end{array}$ \\
\hline
\end{tabular}

a Concn. of total monomers, $0.10 \mathrm{~mol}$; temp, $0^{\circ} \mathrm{C}$; solvent, $\mathrm{CHCl}_{3}$; initiator, $\mathrm{CH}_{3} \mathrm{OSO}_{2} \mathrm{~F}, 1 \mathrm{~mol} \%$ to monomers.

b I, methanol-insoluble fraction; II, methanol-soluble fraction.

c VPO, benzene, $37^{\circ} \mathrm{C}$.

d Initiator, $\mathrm{Et}_{3} \mathrm{OBF}_{4}$.

$$
\begin{aligned}
& \begin{array}{lllll}
b & b & a_{2} & b & b
\end{array} \\
& -\mathrm{OCH}_{2} \mathrm{CH}_{2} \mathrm{OCH}_{2}-\mathrm{OCH}_{2} \mathrm{CH}_{2} \mathrm{OCH}_{2}- \\
& 1 \\
& \text { c d d c c c d d c } \\
& -\mathrm{OCH}_{2} \mathrm{CH}_{2} \mathrm{CH}_{2} \mathrm{CH}_{2}-\mathrm{OCH}_{2} \mathrm{CH}_{2} \mathrm{CH}_{2} \mathrm{CH}_{2}- \\
& 2
\end{aligned}
$$$$
\begin{array}{lllllll}
\text { b } & b & a_{1} & c & d & d & c
\end{array}
$$$$
-\mathrm{OCH}_{2} \mathrm{CH}_{2} \mathrm{OCH}_{2}-\mathrm{OCH}_{2} \mathrm{CH}_{2} \mathrm{CH}_{2} \mathrm{CH}_{2}-
$$$$
3
$$

The peak $\mathrm{a}_{1}$ at $\delta 4.77$ is assignable to the acetal protons adjacent to THF monomer unit. The assignments of the peaks $a_{1}$ and $a_{2}$ are confirmed by model compounds: 3,6,8,11-tetraoxatetradecane 4 and 3,6,8-trioxadodecane 5 show their acetal proton signals at $\delta 4.74$ and $4.77 \mathrm{ppm}$, respectively, which correspond to the peaks $a_{2}$ and $a_{1}$ in the ${ }^{1} \mathrm{H}$ NMR spectrum in Figure 3. However, the acetal proton signals are more properly assigned in terms of the triad sequences to be suggested later.

$$
\begin{gathered}
4.74 \mathrm{ppm} \\
\mathrm{CH}_{3} \mathrm{CH}_{2}-\mathrm{OCH}_{2} \mathrm{CH}_{2} \mathrm{OCH}_{2}-\mathrm{OCH}_{2} \mathrm{CH}_{2} \mathrm{OCH}_{2} \mathrm{CH}_{3} \\
4.77 \mathrm{ppm} \\
\mathrm{CH}_{3} \mathrm{CH}_{2}-\mathrm{OCH}_{2} \mathrm{CH}_{2} \mathrm{OCH}_{2}-\mathrm{OCH}_{2} \mathrm{CH}_{2} \mathrm{CH}_{2} \mathrm{CH}_{3} \\
5
\end{gathered}
$$

In the ${ }^{1} \mathrm{H}$ NMR spectra of the copolymers prepared with $\mathrm{Et}_{3} \mathrm{OBF}_{4}$, no signal corresponding to signal $a_{1}$ in Figure 3 is observed. Therefore, it is very 
Table II. Fractionation of DOL-THF copolymers

\begin{tabular}{|c|c|c|c|c|c|c|c|c|c|c|}
\hline \multirow{2}{*}{$\begin{array}{c}\text { Sample } \\
\text { No. }^{\mathrm{a}}\end{array}$} & \multirow{2}{*}{ Initiator } & \multirow{2}{*}{ [DOL] } & \multirow{2}{*}{$\mathrm{MW}^{\mathrm{c}}$} & & \multicolumn{4}{|c|}{$\begin{array}{l}\text { Hexane-sol } \\
\text { fraction }\end{array}$} & \multirow{2}{*}{$\frac{\begin{array}{c}\text { Hexane-insol } \\
\text { fraction }\end{array}}{4}$} & \multirow{2}{*}{ Total } \\
\hline & & & & & 1 & 2 & 3 & 4 & & \\
\hline 2 & $\mathrm{CH}_{3} \mathrm{OSO}_{2} \mathrm{~F}$ & $0.28_{9}$ & 2300 & $\begin{array}{l}\text { wt fraction, \% } \\
{[\mathrm{DOL}]} \\
\mathrm{MW}^{\mathrm{c}}\end{array}$ & $\begin{array}{l}31.2 \\
0.06_{7} \\
1400\end{array}$ & $\begin{array}{l}11.8 \\
0.13_{5} \\
1400\end{array}$ & $\begin{array}{l}9.8 \\
0.23_{2} \\
1000\end{array}$ & $\begin{array}{l}20.6 \\
0.22_{2} \\
2600\end{array}$ & $\begin{array}{l}14.5 \\
0.61_{2} \\
2500\end{array}$ & $\begin{array}{l}87.9 \\
- \\
-\end{array}$ \\
\hline 4 & $\mathrm{CH}_{3} \mathrm{OSO}_{2} \mathrm{~F}$ & $0.83_{4}$ & 1400 & $\begin{array}{l}\text { wt fraction, \% } \\
\text { [DOL] } \\
\text { MW }^{\mathrm{c}}\end{array}$ & $\begin{array}{l}6.0 \\
0.44_{8} \\
1000\end{array}$ & $\begin{array}{l}3.5 \\
0.56_{5} \\
1100\end{array}$ & $\begin{array}{l}4.1 \\
0.64_{9} \\
1100\end{array}$ & $\begin{array}{l}2.5 \\
0.73_{7} \\
1400\end{array}$ & $\begin{array}{l}77.0 \\
0.95_{5} \\
1400\end{array}$ & $\begin{array}{l}93.1 \\
- \\
-\end{array}$ \\
\hline 7 & $\mathrm{Et}_{3} \mathrm{OBF}_{4}$ & $0.82_{8}$ & 7400 & $\begin{array}{l}\text { wt fraction, } \% \\
{[D O L]} \\
\mathrm{MW}^{\mathrm{c}}\end{array}$ & $\begin{array}{l}0 \\
-\end{array}$ & $\begin{array}{l}3.0 \\
0.45_{1} \\
2000\end{array}$ & $\begin{array}{l}3.5 \\
0.63_{4} \\
3700\end{array}$ & $\begin{array}{l}0.4 \\
0.60_{6} \\
-\end{array}$ & $\begin{array}{c}93.2 \\
0.83_{8} \\
7700\end{array}$ & $\begin{array}{c}100.1 \\
- \\
-\end{array}$ \\
\hline $8^{\mathrm{b}}$ & - & $0.49_{3}$ & - & $\begin{array}{l}\text { wt fraction, \% } \\
\text { [DOL] }\end{array}$ & $\begin{array}{l}9.0 \\
0.02_{3}\end{array}$ & $\begin{array}{l}32.5 \\
0.01_{7}\end{array}$ & $\begin{array}{l}9.7 \\
0.06_{2}\end{array}$ & - & $\begin{array}{l}50.7 \\
0.96_{3}\end{array}$ & $\begin{array}{c}101.9 \\
-\end{array}$ \\
\hline
\end{tabular}

a Sample numbers correspond to those in Table I (methanol-insoluble fraction).

b A mixture of poly(DOL) $\left(M_{n}=2300\right)$ and poly(THF) $\left(M_{n}=3400\right)$.

c VPO, benzene, $37^{\circ} \mathrm{C}$.

likely that a mixture of homopolymers and/or block copolymers of DOL and THF are formed in the cationic copolymerization initiated with $\mathrm{Et}_{3} \mathrm{OBF}_{4}$.

The ${ }^{13} \mathrm{C}$ NMR spectra of the copolymers prepared with $\mathrm{CH}_{3} \mathrm{OSO}_{2} \mathrm{~F}$ show two acetal carbon signals at $\delta 95.6$ and $96.0 \mathrm{ppm}$, while those of the polymers prepared with $\mathrm{Et}_{3} \mathrm{OBF}_{4}$ show a single acetal carbon signal at $\delta 95.6 \mathrm{ppm}$, which corresponds to the acetal carbon of the DOL homopolymer.

The observed differences in the ${ }^{1} \mathrm{H}$ and ${ }^{13} \mathrm{C}$ NMR spectra of these copolymers strongly suggest that the mechanisms of the copolymerizations are different in these two initiator systems.

\section{Fractionation of Copolymers}

Some copolymers and a mixture of DOL- and THF-homopolymers were fractionated into hexanesoluble and -insoluble fractions as described in detail in the Experimental part. The results are listed in Table II. In the case of the homopolymer mixture (No. 8), DOL- and THF-homopolymers were separated almost completely into the hexane-insoluble and -soluble fractions, respectively. On the other hand, in the fractionations of the copolymers prepared with $\mathrm{CH}_{3} \mathrm{OSO}_{2} \mathrm{~F}$ as an initiator (No. 2 and 4), the mole fraction of DOL in the hexane-soluble parts are lower than those in the original copolymers, and those in the haxane-insoluble parts are higher than those in the original copolymers. The variation in the number-average molecular weight of each fraction

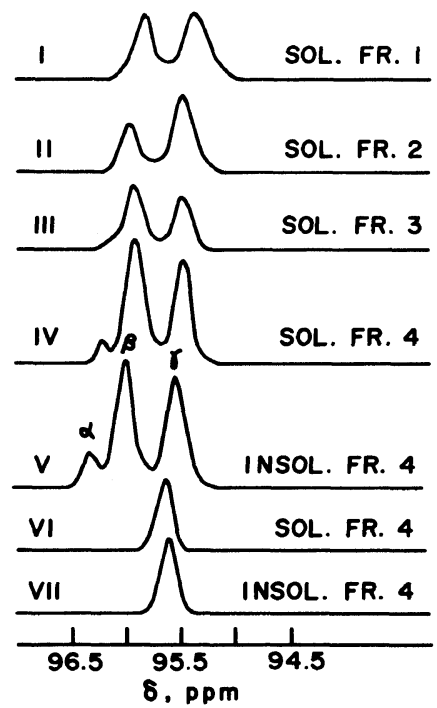

Figure 4. Expanded ${ }^{13} \mathrm{C}$ NMR spectra of acetal carbons of fractionated DOL-THF copolymers: I-V, sample No. 2; VI and VII, sample No. 7. 
seems to indicate that the fractionation is not only due to composition but also due to molecular weight. Taking the aforementioned NMR data into account, the fractionation data on the product obtained with $\mathrm{Et}_{3} \mathrm{OBF}_{4}$ (No. 7) suggest the formation of block copolymers.

Expanded ${ }^{13} \mathrm{C}$ NMR spectra of the acetal carbons of some fractionated polymers are shown in Figure 4. In spectra IV and $\mathrm{V}$, three signals, $\alpha, \beta$, and $\gamma$ are distinctly observed; these probably arise from triad sequences. The signal $\gamma$ at $\delta 95.6 \mathrm{ppm}$ corresponds to that of the acetal carbon in the DOL homopolymer, and is assigned to the acetal carbon in the triad AAA 6. From the chemical shifts of the acetal carbon in 4 and $\mathbf{5}(\delta 95.1$ and $95.3 \mathrm{ppm}$, respectively) the signals $\beta$ and $\alpha$ may be assignable to the acetal carbons in the triads (AAB 7+BAA 8) and BAB 9, respectively, where $A$ and $B$ denote DOL and THF units.

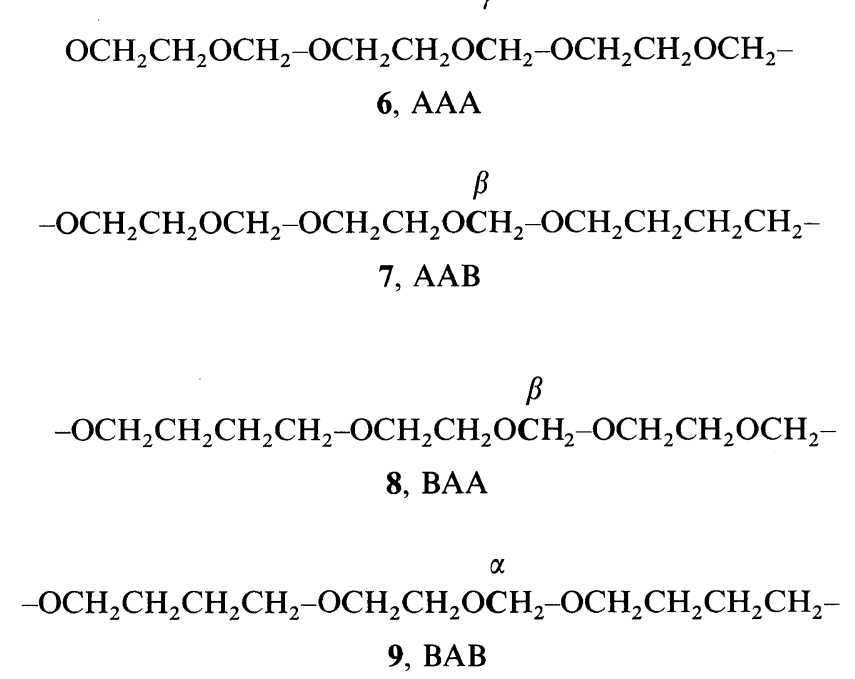

As the relative peak area of the signal $a_{1}$ in Figure 3 is close to that of the signal $\alpha$ in Figure 4, the signal $a_{1}$ in Figure 3 can be assigned to the acetal protons in the triad $\mathrm{BAB}$. Accordingly, the signal $\mathrm{a}_{2}$ should be due to the acetal protons in the triads $\mathrm{AAB}, \mathrm{BAA}$, and AAA. The validity of these assignments is confirmed by the calculation of $\mathrm{AB}$ diad fractions based on the assignments of the three signals $\alpha, \beta$, and $\gamma$, as will be described below. ${ }^{13} \mathrm{C}$ NMR spectra of the hexane-soluble and -insoluble parts of the copolymers prepared with $\mathrm{Et}_{3} \mathrm{OBF}_{4}$ show only one signal, assigned to the acetal carbon in the triad AAA (VI and VII in Figure 4); this indicates that very few $\mathrm{AB}$ diad, if any, are present in the copolymer chain.

\section{Compositions and Diad Fractions}

The mole fraction of DOL in copolymers can be calculated from the relative peak area of the proton signals $a_{1}, a_{2}$, and $d$ in Figure 3.

$$
[A]=2\left(a_{1}+a_{2}\right) /\left\{2\left(a_{1}+a_{2}\right)+d\right\}
$$

$$
[\mathrm{B}]=1-[\mathrm{A}]
$$

where $[A]$ and $[B]$ are the mole fractions of the corresponding units. As mentioned above, the signal $a_{1}$ in Figure 3 is assignable to the acetal protons in the $\mathrm{BAB}$ triad 9, and the diad fraction $[\mathrm{AB}]$ is calculated as follows.

$$
\begin{aligned}
& {[\mathrm{AB}]=[\mathrm{A}] \cdot P_{\mathrm{AB}}} \\
& P_{\mathrm{BAB}}=P_{\mathrm{AB}}^{2}=\mathrm{a}_{1} /\left(\mathrm{a}_{1}+\mathrm{a}_{2}\right)
\end{aligned}
$$

where $P_{\mathrm{AB}}$ and $P_{\mathrm{BAB}}$ define the probabilities of the diad $\mathrm{AB}$ and the triad $\mathrm{BAB}$ in a copolymer chain, respectively; that is, the former is the probability that an $A$ unit has a neighboring $B$ unit and the latter is the probability that an A unit has B units on both sides.

Combining eq 3 and 4 , one obtains

$$
[A B]=[A] \sqrt{\frac{a_{1}}{a_{1}+a_{2}}}
$$


The diad fractions $[\mathrm{AA}]$ and $[\mathrm{BB}]$ are given by eq 6 and 7 .

$$
\begin{aligned}
& {[\mathrm{AA}]=[\mathrm{A}]-[\mathrm{AB}]} \\
& {[\mathrm{BB}]=[\mathrm{B}]-[\mathrm{AB}]}
\end{aligned}
$$

In Table IV, the copolymer compositions and diad fractions of some of the samples are summarized, together with the average sequence lengths, $\bar{l}_{\mathrm{A}}$ and $\bar{l}_{\mathrm{B}}$, and the run number $R$, which refers to the number of sequences per 100 monomer units in a copolymer chain. ${ }^{15}$

$$
\begin{aligned}
& \overline{l_{\mathrm{A}}}=[\mathrm{A}] /[\mathrm{AB}] \\
& \overline{l_{\mathrm{B}}}=[\mathrm{B}] /[\mathrm{AB}] \\
& R=200[\mathrm{AB}]
\end{aligned}
$$

$P_{\mathrm{BAB}}, P_{\mathrm{AAB}}, P_{\mathrm{BAA}}$, and $P_{\mathrm{AAA}}$ define the probabilities of the triads BAB, AAB, BAA, and AAA in a copolymer chain, respectively.

$$
\begin{aligned}
P_{\mathrm{BAB}} & +P_{\mathrm{BAA}}+P_{\mathrm{AAB}}+P_{\mathrm{AAA}}=1 \\
P_{\mathrm{BAB}}= & P_{\mathrm{AB}}^{2}=\left(\frac{[\mathrm{AB}]_{i}}{[\mathrm{~A}]_{i}}\right)^{2}=\frac{\alpha}{\alpha+\beta+\gamma} \\
P_{\mathrm{BAA}} & +P_{\mathrm{AAB}}=2 P_{\mathrm{AA}} P_{\mathrm{AB}} \\
= & 2\left(\frac{[\mathrm{A}]_{i}-[\mathrm{AB}]_{i}}{[\mathrm{~A}]_{i}}\right)\left(\frac{[\mathrm{AB}]_{i}}{[\mathrm{~A}]_{i}}\right) \\
= & \frac{\beta}{\alpha+\beta+\gamma} \\
P_{\mathrm{AAA}} & =P_{\mathrm{AA}}^{2}=\left(\frac{[\mathrm{A}]_{i}-[\mathrm{AB}]_{i}}{[\mathrm{~A}]_{i}}\right)^{2} \\
& =\frac{\gamma}{\alpha+\beta+\gamma}
\end{aligned}
$$

where $\alpha, \beta$, and $\gamma$ mean the relative peak areas of the corresponding acetal carbon signals in Figure 4, $[\mathrm{A}]_{i}$ is the mole fraction of DOL in fractionated copolymers, which is evaluated from the ${ }^{1} \mathrm{H}$ NMR spectra, and the subscript $i$ is the fraction number. The $[\mathrm{AB}]_{i}$ of each fraction can be determined from eq 12-14. The moles of DOL and THF units $A_{i}$ and $B_{i}$, and the cross-over diad $A_{B}$ in each fraction are given by eq 15,16 , and 17 , respectively.

$$
\begin{gathered}
A_{i}=W_{i}\left(\frac{74.08[\mathrm{~A}]_{i}}{72.11\left(1-[\mathrm{A}]_{i}\right)+74.08[\mathrm{~A}]_{i}}\right) \frac{1}{74.08} \\
=W_{i}\left(\frac{[\mathrm{A}]_{i}}{72.11+1.97[\mathrm{~A}]_{i}}\right) \\
\mathrm{B}_{i}=A_{i}\left([\mathrm{~B}]_{i} /[\mathrm{A}]_{i}\right) \\
A B_{i}=A_{i}\left([\mathrm{AB}]_{i} /[\mathrm{A}]_{i}\right)
\end{gathered}
$$

where $[\mathrm{A}]_{i}$ and $[\mathrm{B}]_{i}$ are the mole fractions of DOL and THF units, respectively, in fraction $i$, and $W_{i}$ is the weight of the corresponding fraction. The total $[\mathrm{A}]_{1}$ and $[A B]_{t}$, which should be equal to those of the unfractionated copolymer if the assignments of the signals $\alpha, \beta$, and $\gamma$ in Figure 4 are correct, are calculated from eq 18 and 19 , respectively.

$$
\begin{gathered}
{[\mathrm{A}]_{t}=\frac{\sum_{i=1}^{n} A_{i}}{\sum_{i=1}^{n} A_{i}+\sum_{i=1}^{n} B_{i}}} \\
{[\mathrm{AB}]_{t}=\frac{\sum_{i=1}^{n} A B_{i}}{\sum_{i=1}^{n} B_{i}}}
\end{gathered}
$$

The diad fractions $[\mathrm{AB}]_{i}$ and $[\mathrm{AB}]_{\mathrm{t}}$ were calculated from eq 12-14 and 19, respectively, for the fractionated copolymers (No. 2). The data given in Table III show that the $[\mathrm{AB}]_{i}$ values calculated from the three signals $\alpha, \beta$, and $\gamma$, respectively, in Figure 4 are equal within the experimental error and that the $[\mathrm{AB}]$ diad fraction of the original copolymer, $0.09_{4}$, which is determined from eq 5 , is nearly equal to the $[\mathrm{AB}]_{\mathrm{t}}$ diad fraction $0.07_{7}$, which is calculated from eq 19 . These results indicate that the assignments of the peaks $\alpha, \beta$, and $\gamma$ in Figure 4 are correct.

The composition and diad fractions of the copolymers are summarized in Table IV. All fractions of the copolymers obtained with $\mathrm{CH}_{3} \mathrm{OSO}_{2} \mathrm{~F}$ (No. $2-5)$ contained the cross-over diad $\mathrm{AB}$ in varying amounts, indicating that these were real copolymers of DOL and THF. It must be noted, however, that there are noticeable differences in the copolymer composition and diad fractions between the hexanesoluble and -insoluble parts, and also between the methanol-soluble and -insoluble parts. Such broad 
Table III. Diad fractions, $[\mathrm{AB}],[\mathrm{AB}]_{i}$, and $[\mathrm{AB}]_{t}$ in fractionated DOL-THF copolymer ${ }^{\mathrm{a}}$

\begin{tabular}{|c|c|c|c|c|c|c|}
\hline \multirow{2}{*}{$\begin{array}{c}\text { Sample } \\
\text { No. }\end{array}$} & \multirow{2}{*}{ Fraction No. } & \multicolumn{3}{|c|}{$[\mathrm{AB}]_{i}^{\mathrm{b}}$} & \multirow{2}{*}{$\mathrm{Av}$} & \multirow{2}{*}[\mathrm{AB}]{$^{\mathrm{c}}$} \\
\hline & & $\alpha$ & $\beta$ & $\gamma$ & & \\
\hline & Original & - & - & - & - & $0.09_{4}$ \\
\hline \multirow{6}{*}{2} & Hexane-sol 1 & - & $0.02_{2}$ & $0.01_{9}$ & $0.02_{0}$ & - \\
\hline & 2 & - & $0.03_{7}$ & $0.03_{0}$ & $0.03_{3}$ & - \\
\hline & 3 & - & $0.11_{6}$ & $0.07_{3}$ & $0.09_{5}$ & - \\
\hline & 4 & $0.05_{7}$ & $0.09_{9}$ & $0.07_{5}$ & $0.07_{7}$ & - \\
\hline & Hexane-insol 4 & $0.24_{2}$ & $0.21_{3}$ & $0.23_{0}$ & $0.22_{8}$ & - \\
\hline & {$[\mathrm{AB}]_{t}^{\mathrm{d}}$} & - & - & - & - & $0.07_{7}$ \\
\hline \multicolumn{7}{|c|}{$\begin{array}{l}\text { a Sample number corresponds to that in Table I (methanol-insoluble fraction). } \\
\text { b Calculated from eq } 12-14 \text {. } \\
\text { c Calculated from eq } 5 \text {. }\end{array}$} \\
\hline
\end{tabular}

distributions of the copolymer composition and diad fractions may suggest that this copolymerization cannot be treated statistically by the conventional copolymerization theory. The product prepared with $\mathrm{Et}_{3} \mathrm{OBF}_{4}$ (No. 7) is probably a block copolymer and/or a mixture of the homopolymers, judging from the data given in Tables II and IV. The detectable limit of the cross-over diad AB by means of ${ }^{1} \mathrm{H}$ and ${ }^{13} \mathrm{C}$ NMR spectroscopy seems to be at most $1 \%$ to the total diad fractions. Therefore, the fact that no signal due to the cross-over diad AB was observed in the ${ }^{1} \mathrm{H}$ and ${ }^{13} \mathrm{C}$ NMR spectra implies that there is none or at most a very small amount of the crossover diad in the copolymer obtained with $\mathrm{Et}_{3} \mathrm{OBF}_{4}$.

\section{DISCUSSION}

As described in a previous section, the formation of real copolymers in the cationic copolymerization of DOL with THF initiated with $\mathrm{CH}_{3} \mathrm{OSO}_{2} \mathrm{~F}$ was confirmed by means of ${ }^{1} \mathrm{H}$ and ${ }^{13} \mathrm{C}$ NMR spectroscopy and the fractionation of the copolymers. On the other hand, block copolymers and/or mixtures of homopolymers were formed in the copolymerization with $\mathrm{Et}_{3} \mathrm{OBF}_{4}$. In the cationic polymerization of cyclic ethers and acetals initiated with conventional cationic initiators such as $\mathrm{Et}_{3} \mathrm{OBF}_{4}$ and $\mathrm{BF}_{3} \mathrm{Et}_{2} \mathrm{O}$, the propagation takes place through the oxonium ions ${ }^{12}$ and the oxycarbenium ions, ${ }^{8-11}$ respectively. Therefore, the cationic copolymerization of DOL with $\mathrm{THF}$ initiated with $\mathrm{Et}_{3} \mathrm{OBF}_{4}$ may proceed through the oxonium ion for THF and the oxycarbenium ion for DOL.

The growing species of DOL $\mathbf{1 0}$ is attacked by DOL and THF monomers to from 12 and 13, respectively. The ion $\mathbf{1 2}$ is attacked by other monomers to propagate further. The oxonium ion 13, however, cannot propagate because of the occurrence of an oxonium -exchange reaction: The nucleophilic attack of DOL and THF occurs exclusively on the oxymethylene carbon of the penultimate DOL unit (arrow a) rather than on the $\alpha$-methylene carbon of the THF ring (arrow b), because the positive charge on the former carbon should be higher than that on the latter one, on account of the electronwithdrawing effect of the adjacent oxygen; in addition, the five membered THF oxonium ring is relatively stable. Therefore the attack of THF on the oxonium ion $\mathbf{1 3}$ leads only to an exchange reaction involving the THF unit at the growing chain end. The attack of DOL on 13 generates the ion 12, with its degree of polymerization increased by one compared with that of 10 . In other words, chain growth from the oxonium ion $\mathbf{1 3}$ takes place only by the attack of DOL through the formation of the ion 12, and no AB diads can be formed in the polymer chain. However, the ion $\mathbf{1 0}$ is solvated by THF monomers so the reaction (20) is very slow at the initial stage of the copolymerization. 
Copolymerization of Dioxolane with Tetrahydrofuran

Table IV. Compositions and diad fractions of DOL-THF copolymers

\begin{tabular}{|c|c|c|c|c|c|c|c|c|c|c|}
\hline $\begin{array}{c}\text { Sample } \\
\text { No. }^{a}\end{array}$ & $\begin{array}{c}\text { Fraction } \\
\text { No. }^{\mathrm{a}}\end{array}$ & & {$[\mathrm{A}]$} & {$[\mathrm{B}]$} & {$[\mathrm{AB}]$} & {$[\mathrm{AAA}]^{\mathrm{b}}$} & {$[\mathrm{BB}]^{\mathrm{b}}$} & $I_{\mathrm{A}}$ & $\bar{l}_{\mathrm{B}}$ & $R$ \\
\hline \multirow{9}{*}{2} & \multirow{8}{*}{ I } & Unfractionated $^{c}$ & $0.28_{9}$ & $0.71_{1}$ & $0.09_{4}$ & $0.19_{5}$ & $0.61_{7}$ & 3.1 & 7.6 & 19 \\
\hline & & Fractionated $^{\mathrm{d}}$ & & & & & & & & \\
\hline & & Hexane-sol 1 & $0.06_{7}$ & $0.93_{3}$ & $0.02_{0}$ & $0.04_{7}$ & $0.91_{2}$ & 3.4 & 46.7 & 4 \\
\hline & & 2 & $0.13_{5}$ & $0.86_{5}$ & $0.03_{3}$ & $0.10_{2}$ & $0.83_{2}$ & 4.1 & 26.2 & 7 \\
\hline & & 3 & $0.23_{2}$ & $0.76_{8}$ & $0.09_{5}$ & $0.13_{7}$ & $0.67_{3}$ & 2.4 & 8.1 & 19 \\
\hline & & 4 & $0.22_{2}$ & $0.77_{8}$ & 0.077 & $0.14_{5}$ & $0.70_{1}$ & 2.9 & 10.1 & 15 \\
\hline & & Hexane-insol 4 & $0.61_{2}$ & $0.38_{8}^{\circ}$ & $0.22_{8}$ & $0.38_{4}$ & $0.16_{0}$ & 2.7 & 1.7 & 46 \\
\hline & & $\Sigma^{\mathbf{e}}$ & $0.28_{3}$ & $0.71_{7}$ & $0.07_{7}$ & $0.20_{6}$ & $0.64_{0}$ & 3.7 & 9.3 & 15 \\
\hline & II & Unfractionated $^{\mathfrak{c}}$ & $0.35_{3}$ & $0.64_{7}$ & $0.17_{0}$ & $0.18_{3}$ & $0.47_{7}$ & 2.1 & 3.8 & 34 \\
\hline \multirow[t]{2}{*}{3} & I & Unfractionated $^{\mathfrak{c}}$ & $0.93_{0}$ & $0.07_{0}$ & $0.07_{0}$ & $0.86_{0}$ & $0.00_{0}$ & 13.3 & 1.0 & 14 \\
\hline & II & Unfractionated $^{\mathrm{c}}$ & $0.60_{0}$ & $0.40_{0}$ & $0.21_{2}$ & $0.38_{8}$ & $0.18_{8}$ & 2.8 & 1.9 & 42 \\
\hline \multirow{9}{*}{4} & \multirow{8}{*}{ I } & Unfractionated $^{\mathfrak{c}}$ & $0.83_{4}$ & $0.16_{6}$ & $0.10_{3}$ & $0.73_{1}$ & $0.06_{3}$ & 8.1 & 1.6 & 21 \\
\hline & & Fractionated $^{\mathrm{d}}$ & & & & & & & & \\
\hline & & Hexane-sol 1 & $0.44_{8}$ & $0.55_{2}$ & $0.05_{7}$ & $0.39_{1}$ & $0.49_{5}$ & 7.9 & 9.7 & 11 \\
\hline & & 2 & $0.56_{5}$ & $0.43_{5}$ & $0.09_{9}$ & $0.46_{6}$ & $0.33_{6}$ & 5.7 & 4.4 & 20 \\
\hline & & & $0.64_{9}$ & $0.35_{1}$ & $0.09_{1}$ & $0.55_{8}$ & $0.26_{0}$ & 7.1 & 3.9 & 18 \\
\hline & & 4 & $0.73_{7}$ & $0.26_{3}$ & $0.08_{4}$ & $0.65_{3}$ & $0.17_{9}$ & 8.8 & 3.1 & 17 \\
\hline & & Hexane-insol 4 & $0.95_{6}$ & $0.04_{4}$ & $0.07_{3}$ & $0.91_{2}$ & $0.00_{0}$ & 21.7 & 1.0 & 9 \\
\hline & & $\sum^{e}$ & $0.84_{8}$ & $0.15_{2}$ & $0.08_{8}$ & $0.76_{0}$ & $0.06_{4}$ & 9.6 & 1.7 & 18 \\
\hline & II & Unfractionated $^{\mathrm{c}}$ & $0.62_{8}$ & $0.37_{2}$ & $0.17_{9}$ & $0.44_{9}$ & $0.19_{3}$ & 3.1 & 2.1 & 36 \\
\hline \multirow{2}{*}{5} & I & Unfractionated $^{\mathrm{c}}$ & $0.99_{0}$ & $0.01_{0}$ & - & - & - & - & - & 一 \\
\hline & II & Unfractionated $^{\mathrm{c}}$ & $0.93_{6}$ & $0.06_{4}$ & $0.06_{4}$ & $0.87_{2}$ & $0.00_{0}$ & 14.6 & 1.0 & 13 \\
\hline \multirow{8}{*}{7} & \multirow{7}{*}{ I } & Unfractionated $^{c}$ & $0.82_{8}$ & $0.17_{2}$ & $0.00_{0}$ & - & - & - & - & - \\
\hline & & Fractionated $^{\mathrm{d}}$ & & & & & & & & \\
\hline & & Hexane-sol 2 & $0.45_{1}$ & $0.54_{9}$ & $0.00_{0}$ & - & - & - & - & - \\
\hline & & 3 & $0.63_{4}$ & $0.36_{6}$ & $0.00_{0}$ & - & - & - & - & - \\
\hline & & 4 & $0.60_{6}$ & $0.39_{4}$ & $0.00_{0}$ & - & - & - & - & - \\
\hline & & Hexane-insol 4 & $0.83_{8}$ & $0.16_{2}$ & $0.00_{0}$ & - & - & - & - & - \\
\hline & & $\Sigma^{\mathrm{e}}$ & $0.80_{7}$ & $0.19_{3}$ & $0.00_{0}$ & - & - & - & - & - \\
\hline & II & Unfractionated $^{\mathfrak{c}}$ & $0.50_{5}$ & $0.49_{5}$ & $0.00_{0}$ & - & - & - & - & - \\
\hline
\end{tabular}

a Sample numbers correspond to those in Table $\mathrm{I}$.

b $[\mathrm{AA}]=[\mathrm{A}]-[\mathrm{AB}]$ and $[\mathrm{BB}]=[\mathrm{B}]-[\mathrm{AB}]$.

c Determined from ${ }^{1} \mathrm{H}$ NMR spectra.

d Determined from ${ }^{1} \mathrm{H}$ NMR spectra for [A] and [B], and from ${ }^{13} \mathrm{C}$ NMR spectra for [AB].

e $[A]$ and $[A B]$ were calculated from eq 18 and 19 , respectively. 

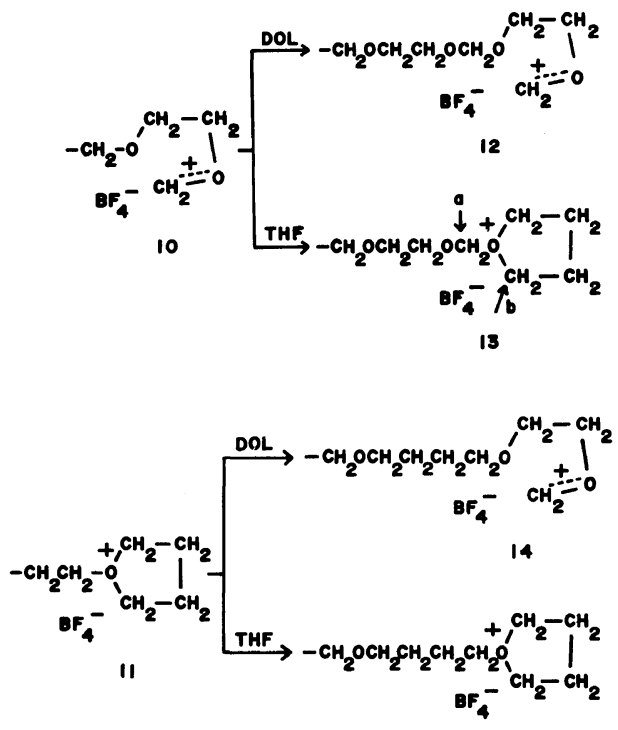

18 results, it seems likely that the ester species of DOL and THF contribute to the formation of the real copolymer described above. Thus, the cross-over diads of DOL-THF and THF-DOL ${ }^{\bullet}$ would be formed by the addition of THF and DOL to the ester species $\mathbf{1 6}$ and $\mathbf{1 7}$, respectively, presumably through the four-membered cyclic transition states $\mathbf{1 8}$ and $\mathbf{1 9}$ (eq 24-26).
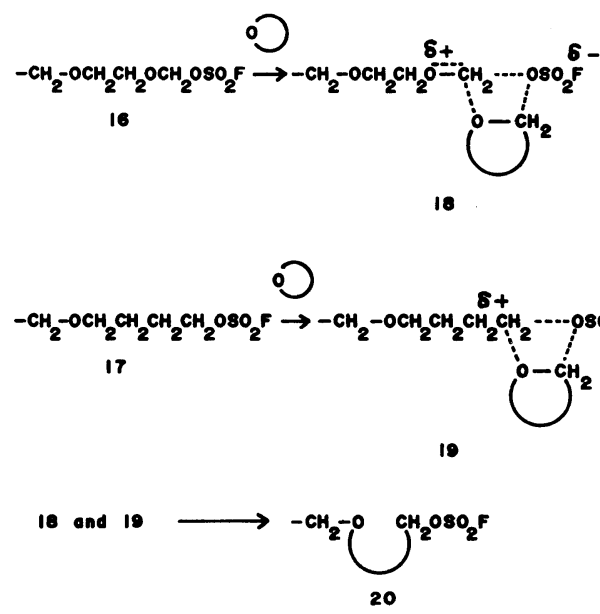

Although there is no direct evidence for the proposed four-membered cyclic transition states, this mechanism seems to be preferable to the conventional $S_{N} 2$ mechanism for the following reason. If the propagation proceeds by $S_{N} 2$ mechanism, there would be formed, although transiently, an ionic species with a $\mathrm{OSO}_{2} \mathrm{~F}^{-}$counter ion. For example, a THF oxonium ion with a penultimate DOL unit would be formed when THF attacks the ester species 16 by an $\mathrm{S}_{\mathrm{N}} 2$ mechanism. Such an oxonium ion cannot propagate because of the oxonium exchange reaction on the oxymethylene carbon of the DOL unit, as described before (eq 21). For the cross-over propagation to occur, the THF oxonium ion must be rapidly transformed to its ester species by the nucleophilic addition of $\mathrm{OSO}_{2} \mathrm{~F}^{-}$counter ion to the $\alpha$-methylene carbon of the THF ring, not to the oxymethylene carbon of the DOL unit, before the oxonium-exchange reaction with DOL monomer takes place. Therefore, the mechanism involving the four-membered cyclic transition states through which ester species are directly formed is probably more reasonable than an $\mathrm{S}_{\mathrm{N}} 2$ mechanism involving the intervention of ionic species.

In summary, DOL-THF copolymers containing 
an appreciable amount of the cross-over diads were obtained in the copolymerization in chloroform with $\mathrm{CH}_{3} \mathrm{OSO}_{2} \mathrm{~F}$ as the initiator, while block copolymers and/or mixtures of homopolymers were formed with $\mathrm{Et}_{3} \mathrm{OBF}_{4}$. The difference in the copolymerization behavior between these two systems suggests that the former system involves the ester growing species $\mathbf{1 6}$ and $\mathbf{1 7}$ which make the cross-over propagations feasible. However, in view of the finding that the distributions of the copolymer composition and diad fractions were rather broad, our results cannot exclude the possibility that ionic growing species may coexist, although in an undetectably low concentration, with the ester growing species in the $\mathrm{CH}_{3} \mathrm{OSO}_{2} \mathrm{~F}$-chloroform system.

\section{REFERENCES}

1. Y. Yokoyama, M. Okada, and H. Sumitomo, Polym. J., 5, 365 (1979).

2. Y. Yamashita, S. Kozawa, K. Chiba, and M. Okada, Makromol. Chem., 135, 75 (1970).

3. E. B. Lyudvig, Z. N. Nysenko, A. K. Khomyakov, and S. S. Medvedev, Preprints, IUPAC Meeting at Budapest, Hungary, August 1969, Vol. 1, p 263; E. B. Lyudvig, E. L. Berman, Z. N. Nysenko, V. A.
Ponomarenko, and S. S. Medvedev, Vysokomol. Soedin., 13, 1375 (1971).

4. M. Okada, N. Takigawa, S. Iwatsuki, Y. Yamashita, and Y. Ishii, Makromol. Chem., 82, 16 (1965).

5. Y. Yamashita, M. Okada, and M. Hirota, Angew. Makromol. Chem., 9, 136 (1969).

6. S. Aoki, Y. Harita, Y. Tanaka, H. Mandai, and T. Otsu, J. Polym. Sci., A-1, 6, 2585 (1968).

7. T. Saegusa, S. Matsumoto, and Y. Hashimoto, Macromolecules, 3, 377 (1970).

8. Y. Yokoyama, M. Okada, and H. Sumitomo, Makromol. Chem., 178, 529 (1977).

9. Y. Yokoyama, M. Okada, and H. Sumitomo, Makromol. Chem., 179, 1393 (1978).

10. M. Okada, Y. Yamashita, and Y. Ishii, Makromol. Chem., 94, 181 (1966).

11. M. Okada, S. Ikai, K. Chiba, M. Hirota, and Y. Yamashita, Polym. J., 1, 1 (1970).

12. For example, T. Saegusa and S. Matsumoto, $J$. Polym. Sci., A-1, 6, 1559 (1968).

13. M. J. Astle, J. A. Zaslowsky, and P. G. Rafyatis, Ind. Eng. Chem., 46, 787 (1954).

14. H. Meerwein, K. Bodenbenner, P. Borner, and K. Wunderlich, Liebigs Ann. Chem., 632, 38 (1960).

15. H. J. Harwood and W. M. Ritchey, J. Polym. Sci., B, 2, 601 (1964).

16. T. Saegusa and S. Kobayashi, J. Polym. Sci., Polym. Symp., No. 56, 241 (1976)

17. S. Penczek and K. Matyjaszewski, J. Polym. Sci., Polym. Symp., No. 56, 255 (1976). 